University of Nebraska - Lincoln

DigitalCommons@University of Nebraska - Lincoln

2012

\title{
Application of day and night digital photographs for estimating maize biophysical characteristics
}

\author{
Toshihiro Sakamoto \\ National Institute for Agro-Environmental Sciences, Tsukuba, Ibaraki, Japan; sakamt@affrc.go.jp \\ Anatoly Gitelson \\ University of Nebraska-Lincoln, agitelson2@unl.edu \\ Brian D. Wardlow \\ University of Nebraska - Lincoln, bwardlow2@unl.edu \\ Timothy J. Arkebauer \\ University of Nebraska - Lincoln, tarkebauer1@unl.edu \\ Shashi Verma \\ University of Nebraska - Lincoln, sverma1@unl.edu \\ See next page for additional authors
}

Follow this and additional works at: https://digitalcommons.unl.edu/natrespapers

Part of the Natural Resources and Conservation Commons

Sakamoto, Toshihiro; Gitelson, Anatoly; Wardlow, Brian D.; Arkebauer, Timothy J.; Verma, Shashi; Suyker, Andrew E.; and Shibayama, Michio, "Application of day and night digital photographs for estimating maize biophysical characteristics" (2012). Papers in Natural Resources. 320.

https://digitalcommons.unl.edu/natrespapers/320

This Article is brought to you for free and open access by the Natural Resources, School of at DigitalCommons@University of Nebraska - Lincoln. It has been accepted for inclusion in Papers in Natural Resources by an authorized administrator of DigitalCommons@University of Nebraska - Lincoln. 


\section{Authors}

Toshihiro Sakamoto, Anatoly Gitelson, Brian D. Wardlow, Timothy J. Arkebauer, Shashi Verma, Andrew E. Suyker, and Michio Shibayama 
Published in Precision Agriculture 13 (2012), pp. 285-301; doi: 10.1007/s11119-011-9246-1

Copyright () 2011 Springer Science+Business Media, LLC. Used by permission.

Published online September 15, 2011.

\title{
Application of day and night digital photographs for estimating maize biophysical characteristics
}

\author{
Toshihiro Sakamoto, ${ }^{1,2}$ Anatoly A. Gitelson, ${ }^{3}$ \\ Brian D. Wardlow, ${ }^{1}$ Timothy J. Arkebauer, ${ }^{4}$ \\ Shashi B. Verma, ${ }^{5}$ Andrew E. Suyker, ${ }^{5}$ and \\ Michio Shibayama ${ }^{2}$
}

1. National Drought Mitigation Center, School of Natural Resources, University of Nebraska-Lincoln, Lincoln, NE, USA

2. Ecosystem Informatics Division, National Institute for Agro-Environmental Sciences, 3-1-3 Kannondai, Tsukuba Ibaraki, 305-8604, Japan

3. Center for Advanced Land Management Information Technologies, School of Natural Resources, University of Nebraska-Lincoln, Lincoln, NE, USA

4. Department of Agronomy and Horticulture, University of Nebraska-Lincoln, Lincoln, NE, USA

5. Great Plains Regional Center for Global Environmental Change, School of Natural Resources, University of Nebraska-Lincoln, Lincoln, NE, USA

Corresponding author - Toshihiro Sakamoto, email sakamt@affrc.go.jp

\begin{abstract}
In this study, an inexpensive camera-observation system called the Crop Phenology Recording System (CPRS), which consists of a standard digital color camera (RGB cam) and a modified near-infrared (NIR) digital camera (NIR cam), was applied to estimate green leaf area index (LAI), total LAI, green leaf biomass and total dry biomass of stalks and leaves of maize. The CPRS was installed for the 2009 growing season over a rainfed maize field the University of Nebraska-Lincoln Agricultural Research and Development Center near Mead, NE, USA. The vegetation indices called Visible Atmospherically Resistant Index (VARI) and two green-red-blue (2g-r-b) were calculated from day-time RGB images taken by the standard commercially-available camera. The other vegetation index called Night-time Relative Brightness Index in NIR (NRBI $\left.{ }_{N I R}\right)$ was calculated from night-time flash NIR images taken by the modified digital camera on which a NIR band-pass filter was attached. Sampling inspections were conducted to measure bio-physical parameters of maize in the same experimental field. The vegetation indices were compared with the biophysical parameters for a whole growing season. The VARI was found to accurately estimate green LAI $\left(R^{2}=0.99\right)$ and green leaf biomass $\left(R^{2}=0.98\right)$, as well as track seasonal changes in maize green vegeta-
\end{abstract}


tion fraction. The $2 \mathrm{~g}-\mathrm{r}-\mathrm{b}$ was able to accurately estimate total LAI $\left(\mathrm{R}^{2}=0.97\right)$. The $\mathrm{NRBI}_{\mathrm{NIR}}$ showed the highest accuracy in estimation of the total dry biomass weight of the stalks and leaves $\left(R^{2}=0.99\right)$. The results show that the camera-observation system has potential for the remote assessment of maize biophysical parameters at low cost.

Keywords: VARI, $2 \mathrm{~g}-\mathrm{r}-\mathrm{b}, \mathrm{NRBI}_{\mathrm{NIR}^{\prime}}$ Night-time flash image, Dry biomass, Crop phenology

\section{Introduction}

The leaf area index (LAI), green biomass, total leaf area and total biomass are closely related to carbon and water balance of plants because they describe the potential plant surface area available for leaf gas exchange between the atmosphere and the terrestrial biosphere (Cowling and Field 2003). Thus, these variables are important parameters controlling many biological and physical processes of vegetation, including the interception of light and water (rainfall and fog), attenuation of light by the canopy, transpiration, photosynthesis, autotrophic respiration and carbon and nutrient (e.g. nitrogen, phosphorus, etc.) cycles. These biophysical parameters are especially important for crops because they are indicators of crop physiological and phenological status, and yield. But on the other hand, conventional destructive measurements of LAI and biomass are both cost and time intensive, which greatly limits the frequency and number of locations for which these types of measures are routinely collected. Therefore, it has been difficult to compile a database of detailed temporal information regarding seasonal changes in biophysical parameters of specific crop variety grown under various climatic and cultivation conditions, which would support on-farm decision-making under varying weather condition. In addition, near real-time information about developmental phase may help a farming corporation which grows various crop species in geographically-dispersed locations to facilitate efficient time-management of production capital such as agricultural machinery, seeds, labor power, storage area for agricultural chemicals and harvested products accordingly. If only to explore potential benefits of information about crop-growth hysteresis on agricultural management, it was required to develop new low-cost, non-destructive approaches using commercially-available digital cameras for continuous observation of seasonal changes in crop growth. The advantage of a camera-based observation system over a single point radiometer is that a digital color image can provide two-dimensional information, which itself enables visual assessment of vegetation fraction, color and shape features of leaves, progression of senescence and impact of extreme weather, disease and pest even though it is a subjective method. In addition, a digital camera does not need additional lighting equipment and can be used for night-time observations because of a built-in flash device. In contrast, spectroscopic observations using a single point radiometer lack visual information on apparent morphological features of a crop community.

A new approach using time-series digital camera image data for crop phenology monitoring was proposed by Sakamoto et al. (2010). They confirmed that the vegetation indices calculated from red-green-blue (RGB) and near-infrared (NIR) information, which were automatically recorded by a system called the Crop Phenology Recording System (CPRS), were very useful for evaluating seasonal changes in the biophysical parameters of rice and barley. The Visible Atmospherically Resistant Index (VARI) (Gitelson et al. 2002) derived from day-time RGB images was found to be closely related to the green vegetation fraction of paddy rice. The Night-time 
Relative Brightness Index (NRBI) derived from night-time flash NIR images was closely related to the total above ground biomass of paddy rice and the plant height of both paddy rice and barley (Sakamoto et al. 2010). Although these findings support the assumption that commercially available digital cameras can provide new information useful for low-cost crop monitoring, further work is needed to test the utility of the CPRS for monitoring the status of other crops.

The goal of this study was to test performance of commercially available cameras for estimating several biophysical characteristics of maize such as green and total LAI, green leaf biomass and above ground biomass. The CPRS was used to collect a time-series of digital images for maize on a rainfed field. Three vegetation indices including VARI, two green-red-blue (2g-r-b; Woebbecke et al. 1995), and $\mathrm{NRBI}_{\mathrm{NIR}}$ were calculated from the CPRS image data and examined for their ability to estimate the set of biophysical characteristics listed above.

\section{Materials and methods}

\section{Maize phenology and agronomic-survey data}

The study was conducted in 2009 in the rainfed maize field that is part of the Carbon Sequestration Program (CSP) at the Agricultural Research and Development Center (http://csp.unl.edu/Public/sites.htm) of the University of Nebraska-Lincoln (UNL) in eastern Nebraska $\left(41^{\circ} 10^{\prime} 46.8^{\prime \prime} \mathrm{N}, 96^{\circ} 26^{\prime} 22.7^{\prime \prime} \mathrm{W}\right)$. The maize variety was "Pioneer 33T57" and the plant population was 6 plants $/ \mathrm{m}^{2}$. The average inter-plant and row distances were 220 and $762 \mathrm{~mm}$, respectively. The dates of major crop developmental stages and farming activities in 2009 are shown in Table 1. The developmental stages used here are those defined in Ritchie et al. (2005), where vegetative stages are those beginning with a $\mathrm{V}$ and reproductive stages are those beginning with an $\mathrm{R}$.

Plant sampling inspection was conducted 14 times from 21 May (DOY 141) to 9 September (DOY 252) to collect the quantitative data on biophysical parameters that included green LAI (GLAI; unit: $\mathrm{m}^{2} / \mathrm{m}^{2}$ ), total LAI (TLAI; unit: $\mathrm{m}^{2} / \mathrm{m}^{2}$ ), dry weights of biomass in separated organs; stalk biomass (SB; unit: $\mathrm{kg} / \mathrm{m}^{2}$ ) including stem, leaf sheaths, immature or undeveloped ears and unfurled leaves, green leaf biomass (GLB; unit: $\mathrm{kg} / \mathrm{m}^{2}$ ), total leaf biomass (TLB; unit: $\mathrm{kg} / \mathrm{m}^{2}$ ), reproductive organs (RB; unit: $\mathrm{kg} / \mathrm{m}^{2}$ ) that included tassel, husk, ear shank, cob, kernels and silks, and plant height (PH; unit: $\mathrm{mm}$ ) (Figure 1; Table 2).

Table 1. Dates of major crop developmental states and farming activities

\begin{tabular}{llll}
\hline Stage/farming activity & Abbr. & Date (2009) & Day of year \\
\hline Planting & PT & April 22 & 112 \\
Emergence & VE & May 7 & 127 \\
First leaf & V1 & May 20 & 140 \\
Third leaf & V3 & May 29 & 149 \\
Seventh leaf & V7 & June 17 & 168 \\
Tasseling & VT & July 8 & 189 \\
Silking & R1 & July 13 & 194 \\
Dent & R5 & August 13-28 & $225-240$ \\
Physiological maturity & R6 & September 14 & 257 \\
Harvesting & HV & November 12 & 316 \\
\hline
\end{tabular}



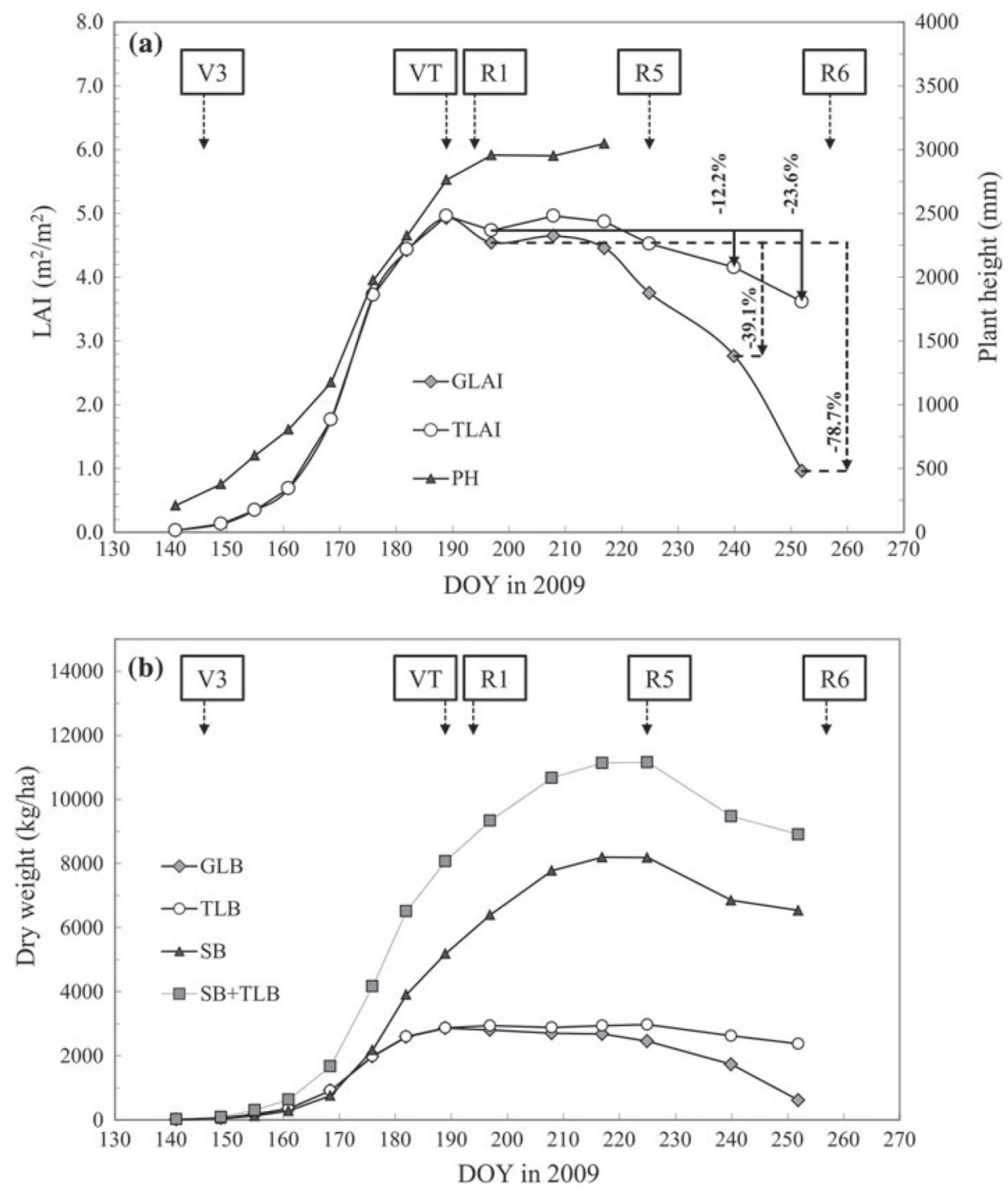

Figure 1. Seasonal changes in field measurements, including a) green LAI, total LAI, plant height, $\mathbf{b}$ ) green leaf biomass, total leaf biomass, stalk biomass and stalk biomass + total leaf biomass.

The dry weights of above ground biomass and leaf area were averaged from destructive samples collected at six locations outside of the camera view. Thus the crop data compared with the camera-based VIs were defined as representative values of biophysical parameters of maize growth in the whole experimental field. The sampling areas were 1-m linear row sections including 4-5 plants. The detail of field measurement protocol is given in Law et al. (2008). The LAI and the other biophysical parameters were destructively measured as follows. First, $\mathrm{PH}$ was measured at six different locations in the field, and then sampling plants were cut off at as close to ground level as possible. Second, plants were separated into green 
Table 2. Objective variables of biophysical parameters

\begin{tabular}{lll}
\hline Biophysical parameters (objective variables) & Unit & $\mathrm{n}$ \\
\hline Green leaf area index (GLAI) & $\mathrm{m}^{2} / \mathrm{m}^{2}$ & 14 \\
Total leaf area index (TLAI; including green and + dead leaves) & $\mathrm{m}^{2} / \mathrm{m}^{2}$ & 14 \\
Stalk biomass (SB) & $\mathrm{kg} / \mathrm{ha}$ & 14 \\
Green leaf biomass (GLB) & $\mathrm{kg} / \mathrm{ha}$ & 14 \\
Total leaf biomass (TLB; including green and dead leaves) & $\mathrm{kg} / \mathrm{ha}$ & 14 \\
Plant height (PH) & $\mathrm{mm}$ & 11 \\
\hline
\end{tabular}

leaves, dead leaves, stalk and reproductive organs in the laboratory. The definition of "green leaves" included all green leaf material from the collar to leaf tip while "dead leaves" were material consisting of greater than $50 \%$ necrotic (or entirely yellow) leaf. The area of sampled green leaves is measured by a Licor LI-3100 leaf area meter (CLI-COR, Lincoln, Nebraska, USA), then the GLAI $\left(\mathrm{m}^{2} / \mathrm{m}^{2}\right)$ were calculated from the destructively-measured green leaf areas $\left(\mathrm{m}^{2}\right)$ with plant population (plant number $\left./ \mathrm{m}^{2}\right)$ of whole field. Dead leaf area $\left(\mathrm{m}^{2}\right)$ was estimated from dry weight of dead leaves $(\mathrm{kg})$ on the basis of specific leaf area of green leaves $\left(\mathrm{kg} / \mathrm{m}^{2}\right)$, which is the ratio of dry weight of green leaves to green leaf area. LAI of dead leaves $\left(\mathrm{m}^{2} /\right.$ $\mathrm{m}^{2}$ ) was also calculated in the basis of plant population. Third, the TLAI was expressed as the sum of the GLAI and the LAI of dead leaves.

\section{Crop Phenology Recording System}

The CPRS consists of two digital cameras protected by custom-made waterproof cases, a rechargeable battery and AC-DC and DC-DC converters (Figure 2). The rechargeable battery, which works as an uninterruptible power source, is connected to a $120 \mathrm{~V}$ AC power supply through the AC-DC converter that supplies the regulated DC electricity to both cameras through the DC-DC converter. A standard Nikon COOLPIX P5100 camera model (@Nikon Corporation, Tokyo, Japan) with no modification (RGB cam) was used to obtain "RGB" images. For the second "NIR cam", the same Nikon camera was used, but modified by replacing the internal NIR-cutoff filter of the original model with a NIR band-pass filter (central wavelength $830 \mathrm{~nm}$, full width at half maximum $260 \mathrm{~nm}$ ) that was attached to the front of the camera lens. Both cameras were installed $3590 \mathrm{~mm}$ above the soil surface and viewed the maize canopy at a depression angle of $90^{\circ}$ looking downward. Each camera automatically took pictures hourly in the interval-shooting mode. Both cameras used the built-in flash device under the "auto flash and auto ISO sensitivity modes" to acquire night-time flash images. The ISO sensitivity plays a role in the gain adjustment when the incident light is converted to an electric signal by the image sensor. The ground area footprint of the images was approximately $3,530 \times 2,650 \mathrm{~mm}$, and the spatial resolution was about $1.7 \mathrm{~mm}$ per pixel at ground level under setup condition of file size (QXGA: 2,048 × 1,536 pixels). Other specific camera settings are shown in Table 3. Figure 3 shows differences in appearance of the maize community recorded in day-time RGB, night-time RGB, day-time NIR and night-time NIR images. As Sakamoto et al. (in press) pointed out in the case study using paddy field, the apparent brightness of maize was darkening at the edges on night-time RGB and NIR images in comparison with the brighter pixels at the central part of the images (Figure $3 b, d)$. This spatial heterogeneity in brightness is because of usage of the point 

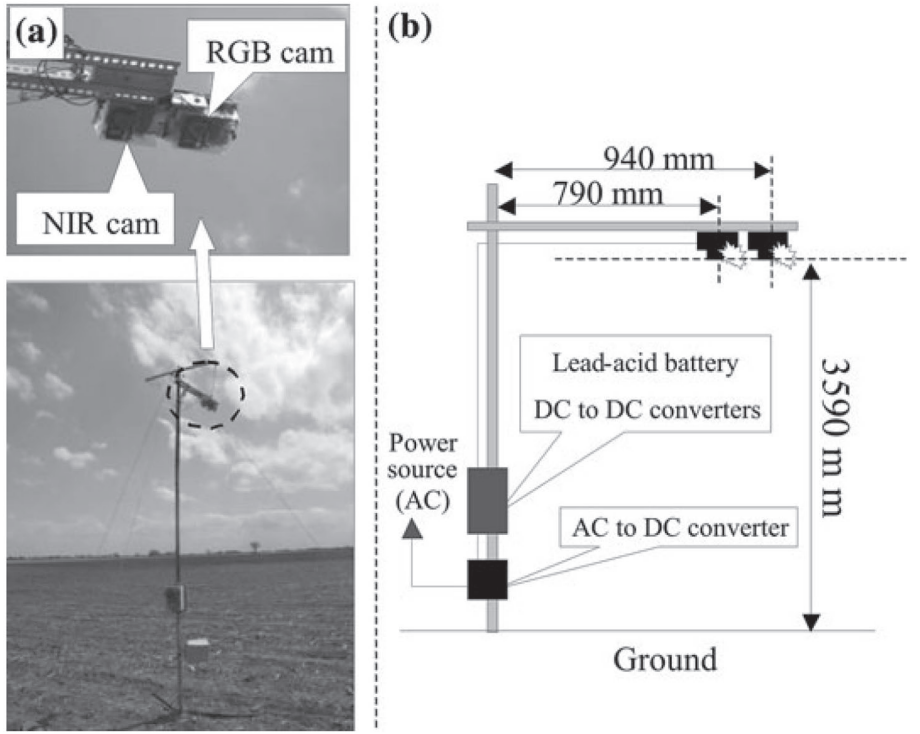

Figure 2. The Crop Phenology Recording System set up in the rainfed corn field, a closeup of the sensor head enclosed in the waterproof housing (a), and a simplified schematic of system installation (b).

Table 3. Specification of Crop Phenology Recording System (CPRS)

\begin{tabular}{lll}
\hline Camera unit name & RGB cam & NIR cam \\
Bands & No ban-pass filter & NIR band-pass filter center: \\
& RGB (Build on & $830 \mathrm{~nm}$, full width: 260 nm \\
detector) & (without IR-cutoff filter) \\
\hline Hardware & Base camera & Nikon COOLPIX P5100 \\
& Illuminator at night time & Build on flash (auto flash mode) \\
& Shooting mode & Programmed auto \\
& Image size & 2 048 $\times 1536$ (QXGA) \\
& File format, compression & Jpeg, Fine \\
& ISO sensitivity & Automatically changed from 64 to 800 \\
& Storage device & SDHC (4 GB) \\
& Interval shooting & Every $1 \mathrm{~h}$ \\
& Auto white balance & Cloud \\
& Other settings & Default \\
Experimental & Height & $3,590 \mathrm{~mm}$ (nadir view) \\
design & Footprint & $3,530 \times 2,650 \mathrm{~mm}$ \\
& Parallax & $152 \mathrm{~mm}$ \\
\hline
\end{tabular}

light source (built-in flash device). Intensity of light is inversely proportional to the square of the distance from the point light source (the built-in flash device) to the object (the crop surface). The optical information recorded in the night-time flash images is supposed to reflect the light scattering characteristics of morphological features of the crop community rather than spectral characteristics. Therefore, day-time RGB images were used to calculate vegetation indices based on color-bands, which are the VARI (Gitelson et al. 2002) and the 2g-r-b (Woebbecke et al. 1995) while 


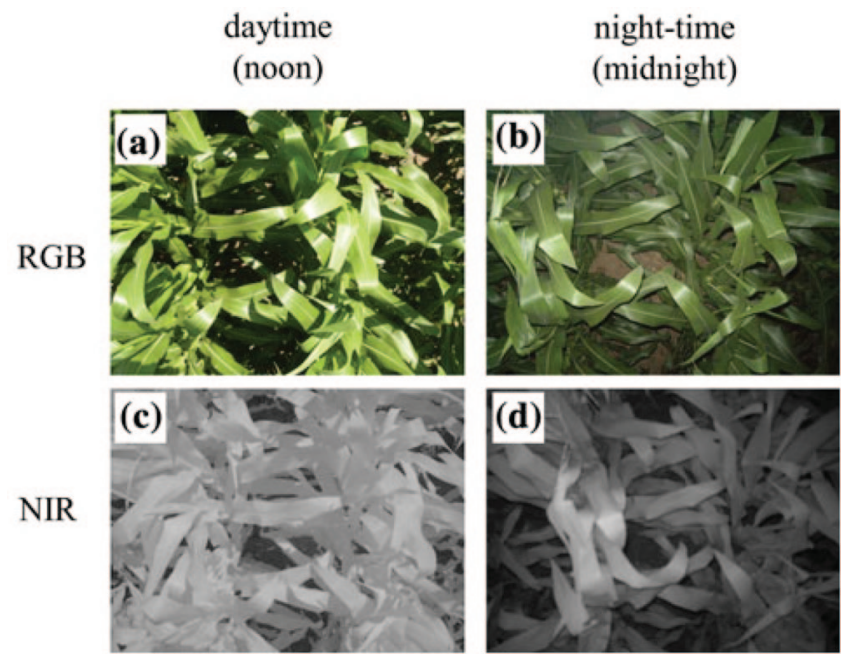

Figure 3. Apparent features of image property seen in day-time RGB (a), night-time RGB (b), day-time NIR (c) and night-time NIR (d) image. The images were acquired at noon and midnight of DOY 195.

night-time NIR images were used to calculate a specific vegetation index called the Night-time Relative Brightness Index in NIR (NRBI ${ }_{\mathrm{NIR}^{\prime}}$ Sakamoto et al. 2010). Continuous field observations using the CPRS were carried out from 9 May (DOY 129) to 17 November (DOY 321) in 2009. Snow piled up to cover the soil surface on 10 October (DOY 283). The CPRS was temporary relocated out of crop-growing area from 11 November to 13 November (DOY 315-317) because of harvesting operation. Figure 4 shows a sample of time-series images acquired during a 10-day interval at noon (RGB image) and midnight (NIR image).

\section{Digital camera-based vegetation indices}

The digital number (DN) of each image pixel, which is the output value of the digital camera, has a non-linear relationship with the intensity of incident light. This non-linear relationship is generally called the gamma characteristic and correction coefficient (gamma value) is usually unpublished by most digital camera manufacturers. Thus, a calibration formula using a 6-degree expression (Matsuda et al. 2003), which was derived from a laboratory experiment using an artificial light source, was applied to calibrate the non-linear relationship between the DN and the intensity of incident light in the same manner as Sakamoto et al. (2010, in press). The DN was first converted into the calibrated digital number (cDN), which has a linear relationship with the relative intensity of incident light (see Sakamoto et al. (2010), for detail about the data pre-processing).

The equations of digital-camera based VIs are as follows:

$$
\begin{gathered}
\text { VARI }=\left(\mathrm{cDN}_{\text {green }}-\mathrm{cDN}_{\text {red }}\right) /\left(\mathrm{cDN}_{\text {green }}+\mathrm{cDN}_{\text {red }}\right) \\
2 \mathrm{~g}-\mathrm{r}-\mathrm{b}=2 \times \mathrm{CDN}_{\text {green }}-\mathrm{cDN}_{\text {red }}-\mathrm{cDN}_{\text {blue }} \\
\mathrm{NRBI}_{\mathrm{NIR}}=\mathrm{cDN}_{\mathrm{NIR}} \times 2^{-(2 \log 2(\mathrm{~F})-\log 2(\mathrm{~T})-\log 2(\mathrm{ISO} / 64))}
\end{gathered}
$$




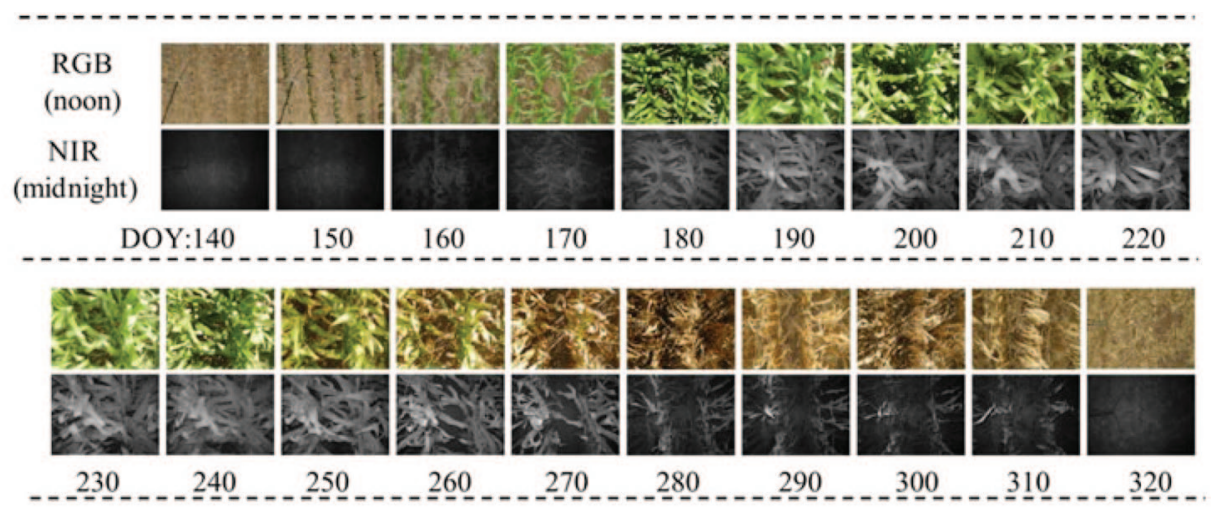

Figure 4. The time-series digital-camera images acquired every 10 days by RGB cam at noon and NIR cam at midnight from DOY 140 to 320.

where $\mathrm{cDN}_{\text {red }}, \mathrm{CDN}_{\text {green, }}$ and $\mathrm{cDN}_{\text {blue }}$ are daily-averaged $\mathrm{cDN}$ obtained from each layer of the day-time RGB images, $\mathrm{cDN}_{\mathrm{NIR}}$ is a daily-averaged $\mathrm{cDN}$ obtained from second layer of the night-time NIR images, F is F-stop, which is also called aperture value (unit: Av), T is exposure time (unit: second), which is also called shutter speed, and ISO is the ISO sensitivity (unitless). The assigned values of camera parameters (F, T and ISO) were extracted from the header region of EXIF formatted JPEG files. According to the laboratory experiment calibrating gamma characteristic of the imaging element of the camera, a stronger linear relationship between the $\mathrm{cDN}$ and the relative light intensity was observed at lower cDN values (Sakamoto et al. 2010). Considering the second-layer cDN of the night-time NIR images tended to be lower than the first- and third-layer cDNs, the cDN of the second-layer NIR image was assigned as $\mathrm{cDN}_{\mathrm{NIR}}$ in Equation 3.

Another laboratory experiment was conducted to measure the spectral profile of the built-in camera flash device using the USB 2000 miniature fiber optic spectrometer (@Ocean Optics, Florida, USA). The trigger button of the spectrometer was manually pushed at the same time as the flash light was emitted in a dark room. The scanning time of the spectrometer, which is the predetermined period to integrate the observed spectral profile on the basis of digital count was $4 \mathrm{~ms}$. The observation was conducted three times. Because each output profile included a lot of high-frequency noise components caused by the short integration time, a 10-nm moving average was performed to smooth each spectral profile. Then, the three observations were averaged to acquire the smoothed spectroscopic property of the camera flash. It was confirmed that there was not much difference in relative light intensity between NIR and visible light range (Figure 5).

The VARI and 2g-r-b were derived from the day-time RGB images taken between 10.00 and 14.00. The NRBI $_{\text {NIR }}$ was derived from the night-time flash NIR images taken between 22.00 and 2.00 (next day). In the literature, the VARI concept was also used under different names or abbreviations such as the "VI = DIF/SUM" (Tucker 1979), "NDI" (Perez et al. 2000), and "NDVIgr" (Sakamoto et al. 2010). The $2 \mathrm{~g}-\mathrm{r}-\mathrm{b}$ has also been referred to by different abbreviations that include ExG (Meyer et al. 1999; Meyer and Neto 2008) and 2G_RBi (Richardson et al. 2007).

The hourly VARI and $2 \mathrm{~g}-\mathrm{r}-\mathrm{b}$ data fluctuate due to various factors such as shadow, light quality (diffused or direct solar radiation) and flapping leaves, which are caused by ever-changing sun zenith angle and weather conditions. Therefore, 
Figure 5. Spectral profile of camera flash measured by the USB 2000 Miniature Fiber Optic Spectrometer.

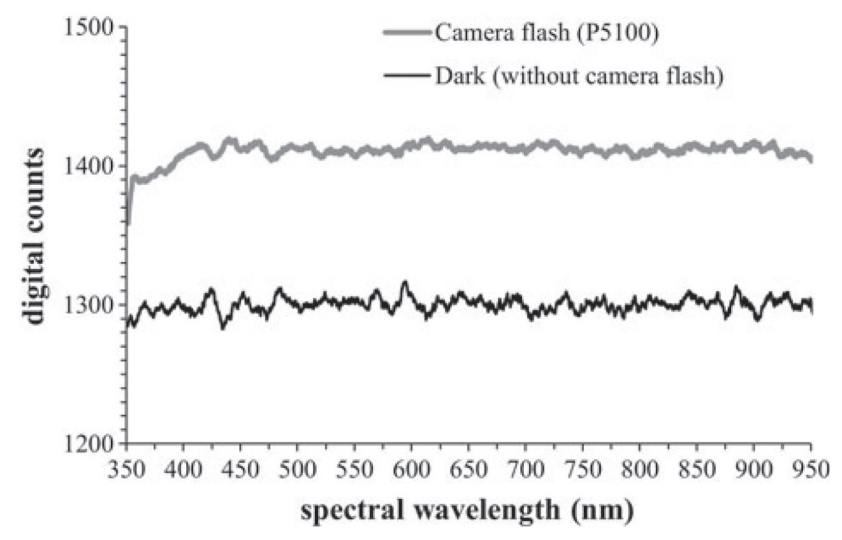

the following averaging procedures were performed to reduce these noise components and acquire seasonal profiles of VIs. First, area-averaged $\mathrm{cDN}_{\text {(red, green or blue) }}$ was calculated using whole pixels from an hourly day-time RGB image, then the five hourly values of the area-averaged $\mathrm{cDN}_{\text {(red, green or blue) }}$ were averaged to obtain a daily-averaged $\mathrm{cDN}_{\text {(red, green or blue) }}$. Second, daily VARI and $2 \mathrm{~g}-\mathrm{r}-\mathrm{b}$ were calculated from the day-time daily-averaged $\mathrm{CDN}_{(\text {red, green and blue) }}$ using Equations 1 and 2. Third, a 7-day moving average was applied to the time-series VIs to obtain smoothed profiles of VARI and 2g-r-b in the same way as Sakamoto et al. (2010).

For night-time, daily-averaged $\mathrm{cDN}_{\mathrm{NIR}}$ was derived in the same way as the daytime daily-averaged $\mathrm{cDN}_{\text {(red, green or blue)' }}$ except for usage of night-time NIR images taken with a flash light. Although night-time flash images were supposed to avoid the effects of sun zenith angle and ever-changing incident light intensity, the timeseries $\mathrm{NRBI}_{\mathrm{NIR}}$ data fluctuated due to the influence of wind and dew. In addition, the night-time $\mathrm{cDN}_{\mathrm{NIR}}$ values were spatially biased within the night-time image due to use of the point light source as shown in Figure 3. Therefore, area-averaged $\mathrm{CDN}_{\mathrm{NIR}}$ using whole image pixels was required to obtain $\mathrm{NRBI}_{\mathrm{NIR}}$, which is supposed to be the representative value of the relative intensity of light scattered from the whole viewing field.

\section{Comparison with agronomic-survey data and $N R B I_{N I R}$ observed in paddy and barley fields}

The dataset of paddy rice and barley, which were obtained in 2007 and 2008 in the previous study (Sakamoto et al. 2010), were compared to this study result using maize to investigate dependence of $\mathrm{NRBI}_{\mathrm{NIR}}$ on crop species. The plant height of paddy rice and barley and above-ground total dry biomass (including panicles) were measured in reference to the night-time camera observations. However, the previous study had a problem with its prototype camera-observation system using ready-made inexpensive waterproof cases (DiCAPac (C) Daisaku Shoji Ltd., Tokyo, Japan), which were not adequately fitted to the cameras and obscured the flash light causing a large shaded area on night-time NIR images. Although the partial area available for calculating night-time $\mathrm{CDN}_{\mathrm{NIR}}$ was limited to a small region $(512 \times 512$ pixels $)$ against the whole image size $(2,048 \times 1,536$ pixels $)$ in the previous study, there were no differences between the previous and the current studies in $\mathrm{NRBI}_{\mathrm{NIR}}$ calculation (Equation 3) and the sensor calibration. New custom-made waterproof cases solved this problem and made it possible to use a whole night-time 
image without large self-shadow area. The height of camera-installation position was varied depending on the experiment, thus the dynamic range of $\mathrm{NRBI}_{\mathrm{NIR}}$ was normalized from 0 (minimum) to 1 (maximum) when comparing the sensitivity of $\mathrm{NRBI}_{\mathrm{NIR}}$ to the agronomic-survey data among the different experiments.

\section{Results and discussion}

\section{Visual analysis of the time-series RGB images}

The characteristics of maize appearance (Figure 6) can be broadly grouped into three growing periods: (1) the vegetative stage (DOY 140-193), (2) the first half of reproductive stage (DOY 194-224) and (3) the last half of reproductive stage (DOY 225-255).

During the vegetative stage from V1 to tasseling (DOY 140-193), the two main crop elements observed in the day-time RGB images were the green biomass consisting of live leaves and stalks and the brown background soil surface. As the vegetative stage progressed, the green vegetation coverage area rapidly expanded to veil the background soil surface of the inter-row and inter-plant spaces.

During the first half of the reproductive stage after tasseling and before the R5 stage (DOY 194-224), the vegetative coverage area (vegetation fraction) was almost invariant while small but different color crop elements (i.e., non-photosynthetic materials) appeared in the camera's field of view (FOV), which consisted of pale yellow tassels, silks, and partially-withered leaves. At the same time, the background soil surface was still observed over a small area of the camera's FOV in the inter-row spaces.

During the last half of the reproductive stage from R5 to R6 stage (DOY 225255), the brown background soil surface was gradually exposed to view while the green leaves and stems withered and turned a yellowish color with progression of the ripening process and senescence.

Comparison of the agronomic-survey data with the camera-based indices

The determination coefficients $\left(\mathrm{R}^{2}\right)$ and the root mean square errors (RMSE) were used to characterize the relationships between maize biophysical parameters and the smoothed-camera VIs (Figure 6; Table 4). It was found that each index had close relationships with different maize biophysical parameters. The VARI had the highest accuracy in estimating the GLAI $\left(R^{2}=0.986, \operatorname{RMSE}=0.220 \mathrm{~m}^{2} / \mathrm{m}^{2}\right)$ and GLB $\left(R^{2}=0.98, R M S E=154 \mathrm{~kg} / \mathrm{ha}\right)$. The $2 \mathrm{~g}-\mathrm{r}-\mathrm{b}$ had the highest correlation with the TLAI $\left(\mathrm{R}^{2}=0.972\right.$, RMSE $\left.=0.322 \mathrm{~m}^{2} / \mathrm{m}^{2}\right)$. The NRBI $\mathrm{NIR}_{\mathrm{R}}$ had the highest correlation with the SB + TLB (total dry weight of stalk biomass plus total leaf biomass) $\left(\mathrm{R}^{2}=0.991\right.$, RMSE $\left.=402 \mathrm{~kg} / \mathrm{ha}\right)$. Figure 7 shows relationships between these specific camera-VIs and the measured biophysical parameters.

\section{Temporal profiles of the camera-VI and the maize biophysical parameters}

Day-time camera-VI (VARI and $2 g-r-b)$

Figure 6a shows the temporal profiles of the VARI and $2 \mathrm{~g}-\mathrm{r}-\mathrm{b}$. During the vegetative stage (DOY 140-193), both indices increased in response to the increase in green vegetation coverage. The VIs showed similar sigmoid-curve increase patterns to the LAI measured during the same period. Both VIs and LAI rapidly increased at an ex- 

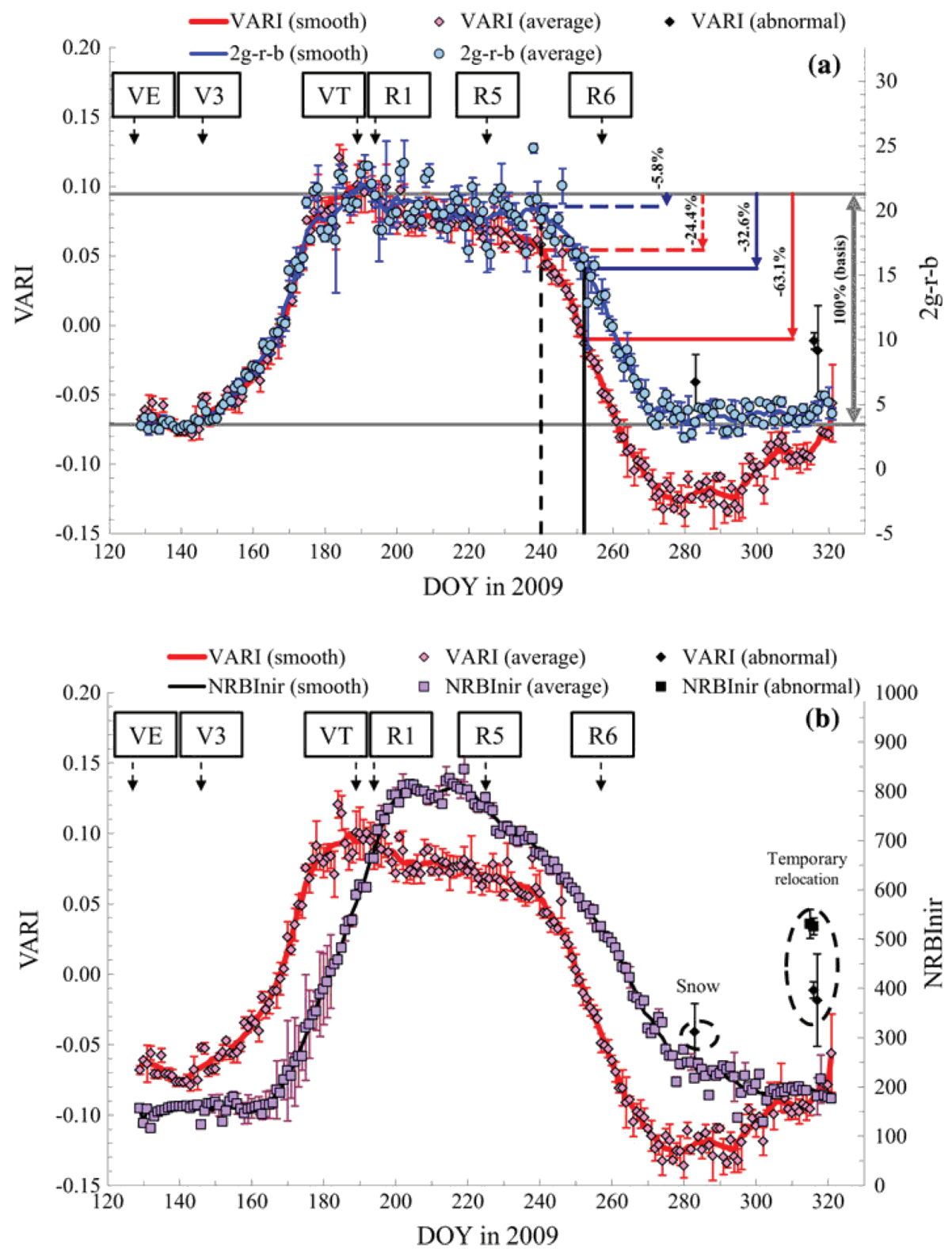

Figure 6. Seasonal changes in VARI (a and $\mathbf{b}), 2 \mathrm{~g}-\mathrm{r}-\mathrm{b}(\mathbf{a})$ and $\mathrm{NRBI}_{\mathrm{NIR}}(\mathbf{b})$ observed in maize field.

ponential rate from DOY 140 to 170 and then peaked at around the VT stage (DOY 189) (Figures 1a, 6a). While the increasing pattern of VARI was consistent with that of the $2 \mathrm{~g}-\mathrm{r}-\mathrm{b}$ during the vegetative stage, the noticeable difference in temporal features between the VARI and the $2 \mathrm{~g}-\mathrm{r}-\mathrm{b}$ could be identified in the decreasing indices after DOY 194. The VARI decreased at a more rapid rate than the TLAI during the reproductive stage. On the basis of amplitudes of VARI ( -0.071 to 0.095$)$ and $2 \mathrm{~g}-\mathrm{r}-\mathrm{b}$ (3.45-21.3) which were defined from the data of vegetative stage (DOY 135-195), the 
Table 4. Summary of estimation accuracy for estimating the seasonal changes in bio-physical parameters with VARI, 2g-r-b and NRBI ${ }_{N I R}$

\begin{tabular}{|c|c|c|c|c|c|c|}
\hline \multirow[t]{2}{*}{ Object } & \multicolumn{2}{|l|}{ VARI } & \multicolumn{2}{|c|}{$2 g-r-b$} & \multicolumn{2}{|c|}{$\mathrm{NRBI}_{\mathrm{NIR}}$} \\
\hline & $\mathrm{R}^{2}$ & RMSE & $\overline{R^{2}}$ & RMSE & $\mathrm{R}^{2}$ & RMSE \\
\hline $\operatorname{GLAI}\left(\mathrm{m}^{2} / \mathrm{m}^{2}\right)$ & 0.986 & 0.220 & 0.894 & 0.601 & 0.652 & 1.09 \\
\hline GLB (kg/ha) & 0.981 & 154 & 0.906 & 340 & 0.707 & 600 \\
\hline $\mathrm{PH}(\mathrm{mm})$ & 0.926 & 294 & 0.942 & 259 & 0.975 & 171 \\
\hline TLAI $\left(\mathrm{m}^{2} / \mathrm{m}^{2}\right)$ & 0.909 & 0.581 & 0.972 & 0.322 & 0.929 & 0.513 \\
\hline $\operatorname{TLB}(\mathrm{kg} / \mathrm{ha})$ & 0.859 & 445 & 0.943 & 284 & 0.966 & 218 \\
\hline SB + GLB (kg/ha) & 0.720 & 2192 & 0.822 & 1746 & 0.988 & 455 \\
\hline $\mathrm{SB}+\mathrm{TLB}(\mathrm{kg} / \mathrm{ha})$ & 0.667 & 2509 & 0.786 & 2009 & 0.991 & 402 \\
\hline $\mathrm{SB}(\mathrm{kg} / \mathrm{ha})$ & 0.580 & 2089 & 0.704 & 1754 & 0.982 & 431 \\
\hline
\end{tabular}
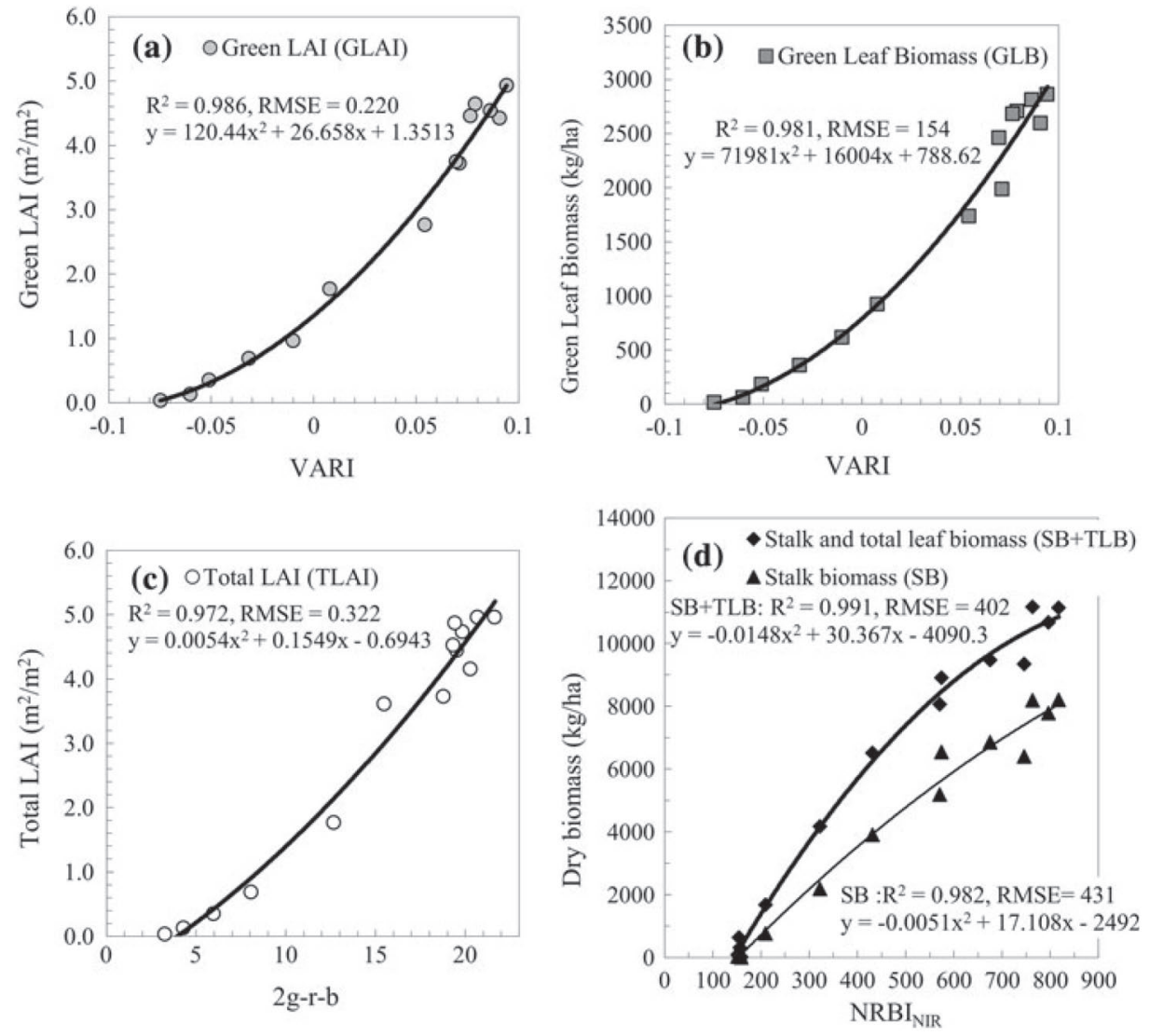

Figure 7. Comparison between the field-measured biophysical parameters and the CPRSderived indices including a) VARI vs. GLAI, b) VARI vs. GLB, c) $2 g-r-b$ vs. TLAI, and d) $\mathrm{NRBI}_{\mathrm{NIR}}$ vs. SB or SB + TLB.

VARI declined considerably by $24.4 \%$ while the $2 \mathrm{~g}-\mathrm{r}-\mathrm{b}$ declined slightly by $5.8 \%$ until DOY 240 (Figure 6a). Then, the difference between the two indices noticeably increased after DOY 240. The VARI had declined by $63.1 \%$ at DOY 252; this decline was 
at a much greater rate than that of the $2 \mathrm{~g}-\mathrm{r}-\mathrm{b}(32.6 \%)$. The temporal features of the VARI and the $2 \mathrm{~g}-\mathrm{r}-\mathrm{b}$ were similar to those of GLAI and TLAI, respectively. The TLAI declined by $12.2 \%$ at DOY 240 and by $24.2 \%$ at DOY 252 on the basis of the TLAI at DOY 197. In contrast, the GLAI showed much noticeable reduction in the same periods; 39.1\% at DOY 240 and $78.8 \%$ at DOY 252 (Figure 1a). Considering the subjectivity in definition of the GLAI (whether leaves are green or not), especially late in the season, the result indicated that the VARI was more sensitive to the change in ratio of green leaves to dead leaves than the $2 \mathrm{~g}-\mathrm{r}-\mathrm{b}$. This is consistent with Gitelson et al. (2002), who suggested that VARI was a proxy of green vegetation fraction. In contrast, the $2 \mathrm{~g}-\mathrm{r}-\mathrm{b}$ had a lower sensitivity to the green vegetation fraction, but more accurately estimated total leaf area (Table 4; Figure 7c).

VARI had a stronger relationship with the GLAI $\left(R^{2}=0.986, \operatorname{RMSE}=0.220\right)$ and GLB $\left(R^{2}=0.981\right.$, RMSE $\left.=154 \mathrm{~kg} / \mathrm{ha}\right)$ than with the TLAI $\left(\mathrm{R}^{2}=0.909, \mathrm{RMSE}=0.581\right)$ and TLB $\left(\mathrm{R}^{2}=0.859, \mathrm{RMSE}=445 \mathrm{~kg} / \mathrm{ha}\right)$. In contrast, the $2 \mathrm{~g}-\mathrm{r}-\mathrm{b}$ exhibited a stronger relationship with the TLAI $\left(R^{2}=0.972, \operatorname{RMSE}=0.322\right)$ and the TLB $\left(\mathrm{R}^{2}=0.943\right.$, RMSE $=284 \mathrm{~kg} / \mathrm{ha})$ than with the GLAI $\left(\mathrm{R}^{2}=0.894\right.$, RMSE $\left.=0.601\right)$ and GLB $\left(\mathrm{R}^{2}=0.906, \mathrm{RMSE}=340 \mathrm{~kg} / \mathrm{ha}\right)$. Thus, the time-series data of VARI and $2 \mathrm{~g}-\mathrm{r}-\mathrm{b}$ derived from day-time RGB images collected from the fixed-point observation using the camera, were able to accurately estimate seasonal changes in the green LAI and leaf biomass and the total LAI and leaf biomass, respectively. The most significant finding from the camera-based VI was that the VARI was able to estimate green LAI across the whole growing season period. Green LAI is an important parameter because of its high correlation with chlorophyll content per unit ground area during a plant's growth cycle, which is superior to total LAI as an indicator for estimating seasonal changes in photosynthetic capacity (Ciganda et al. 2008).

\section{Night-time camera-VI (NRBI $\left.I_{N I R}\right)$}

Figure $6 \mathrm{~b}$ shows the temporal profiles of the $\mathrm{NRBI}_{\mathrm{NIR}}$ with the VARI profile for reference. During the early vegetative stages from the V1 to V6 stage (DOY 140160), the $\mathrm{NRBI}_{\mathrm{NIR}}$ remained at a near constant low level (avg. = 154.9, SD = 7.2). Unlike the VARI, the $\mathrm{NRBI}_{\mathrm{NIR}}$ did not significantly increase in response to the expansion of the green vegetative cover area until the TLAI and PH were over $0.6 \mathrm{~m}^{2} / \mathrm{m}^{2}$ and $800 \mathrm{~mm}$, respectively. This lagged response can be attributed to the fact that the ISO sensitivity was not high enough (ISO = 800) under the illumination intensity of flash irradiated from the camera installation height (3 $590 \mathrm{~mm}$ ). As seen in Figure 4 (DOY 150-160), the contrasts between the vegetative coverage area and the background soil surface in night-time NIR images were less than those in day-time RGB images. This was because the camera flash gave insufficient illumination to light up the small plants separately from the background. After the V6 stage (DOY 160), the NRBI ${ }_{\text {NIR }}$ linearly increased like a sigmoid curve until DOY 217 (avg. = 817.7), when it gradually decreased with a gentle slope until DOY 305 (avg. = 178.5). Although the TLAI reached its maximum value $\left(4.96 \mathrm{~m}^{2} / \mathrm{m}^{2}\right)$ on DOY 189 corresponding to the peak of the VARI at the R1 stage (DOY 194), the $\mathrm{NRBI}_{\mathrm{NIR}}$ continued to increase after the R1 stage when the vegetative fraction became invariant. The agricultural-survey data indicated that the temporal profile of the $\mathrm{NRBI}_{\mathrm{NIR}}$ was less similar than the other two VIs to the TLAI and GLAI (Figures 1a, 6b). Instead, the curve features of the $\mathrm{NRBI}_{\mathrm{NIR}}$ observed between DOY $=160$ and DOY $=250$ were similar to the temporal behavior of the SB and the SB + TLB, as well as the PH (Figure 1). 
Comparison of the relationship of $\mathrm{NRBI}_{\mathrm{NIR}}$ with each biophysical parameter (Table 4; Figure 7c) confirmed that the correlations of the $\mathrm{NRBI}_{\mathrm{NIR}}$ with the SB + TLB $\left(R^{2}=0.991\right)$, the SB $\left(R^{2}=0.982\right)$, and the PH $\left(P H: R^{2}=0.975\right)$ were higher than those with the GLAI $\left(R^{2}=0.652\right)$ and the TLAI $\left(R^{2}=0.929\right)$. This suggests that the $\mathrm{NRBI}_{\mathrm{NIR}}$ has a strong sensitivity to the morphological character of maize $\mathrm{PH}$, which is inextricably associated with the camera-to-object distance, and three-dimensional characteristics such as bulk density related to the above-ground dry biomass (SB + TLB, SB).

Given that the $\mathrm{NRBI}_{\mathrm{NIR}}$ is based on a new remote sensing approach using nighttime flash images, the seasonal pattern of the $\mathrm{NRBI}_{\mathrm{NIR}}$ should be interpreted differently from those of the conventional camera VIs calculated from the day-time RGB images. The point of taking night-time NIR images is not for measuring spectral reflectivity of crop in the NIR region. As expressed in Eq. 3, the $\mathrm{NRBI}_{\mathrm{NIR}}$ is expected to detect relative changes in the intensity of incident light, which is emitted from the built-in flash device and scattered by the maize plant body. Assuming that flash irradiated from a point light source (i.e., built-in flash device) with constant energy diffuses conically in the direction of the target(s) (i.e., soil and plant surface), photon flux density is expected to decrease in proportion to the square of the distance from the light source. Therefore, a well-grown plant canopy having higher biomass, LAI and plant height (shorter camera-to-object distance) would reflect more NIRwavelength light photons toward the camera lens. Sakamoto et al. (in press) investigating rice growth, found that the ISO sensitivity used in the $\mathrm{NRBI}_{\mathrm{NIR}}$ was closely related to the camera-to-object distance and the $\mathrm{NRBI}_{\mathrm{NIR}}$ was responding to the seasonal changes in the three dimensional morphology of the rice stands. In addition, the $\mathrm{NRBI}_{\mathrm{NIR}}$ had high correlation with total dry biomass 20 days after the heading date $\left(R^{2}=0.997\right)$. However, the $\mathrm{NRBI}_{\mathrm{NIR}}$ did not track the temporal changes in dry biomass during the late ripening period of rice because the $\mathrm{NRBI}_{\mathrm{NIR}}$ decreased due to the panicles sagging under their own weight. In the case of maize, the correlation of the $\mathrm{NRBI}_{\mathrm{NIR}}$ with the total above-ground biomass including the ears $\left(\mathrm{R}^{2}=0.772\right)$ was significantly lower than that with SB + TLB. This lower correlation is likely due to the fact that the maize ears were covered under the top-layer leaves of maize canopy and rarely appeared in the acquired images unlike the rice panicles that were over the vegetation canopy Thus, it was assumed that the reproductive organs, especially of the maize ears, did not affect the $\mathrm{NRBI}_{\mathrm{NIR}}$.

The relationships between the normalized $\mathrm{NRBI}_{\mathrm{NIR}}$ and the agronomic-survey data are shown in Figure 8a for above-ground dry biomass of maize and rice and Figure $8 \mathrm{~b}$ for plant height of maize, rice and barley. The relationships of the normalized $\mathrm{NRBI}_{\mathrm{NIR}}$ to above-ground total dry biomass of maize (excluding ears) and rice were very close to linear in comparison with those to the plant height of maize, rice and barley. Based on these results, the $\mathrm{NRBI}_{\mathrm{NIR}}$ was found to be useful for detecting the seasonal changes in the three-dimensional characteristic of above-ground biomass such as dry biomass weight and plant height, regardless of crop species.

While commercially available digital cameras are increasingly being equipped with various advanced functions, the spectral sensitivity characteristic of the imaging element and the internal parameters for automatic image compensation are not available from the manufacturer. It is still unknown how the changed camera height and plant density affect the camera-based VIs. Moreover, the CPRS requires long-term agronomic-survey data collected during the entire growing period for system calibration in the specific attempt to evaluate seasonal changes in crop biophysical parameters. Therefore, further research with additional field campaigns needs to be conducted to collect additional experimental data under various experi- 

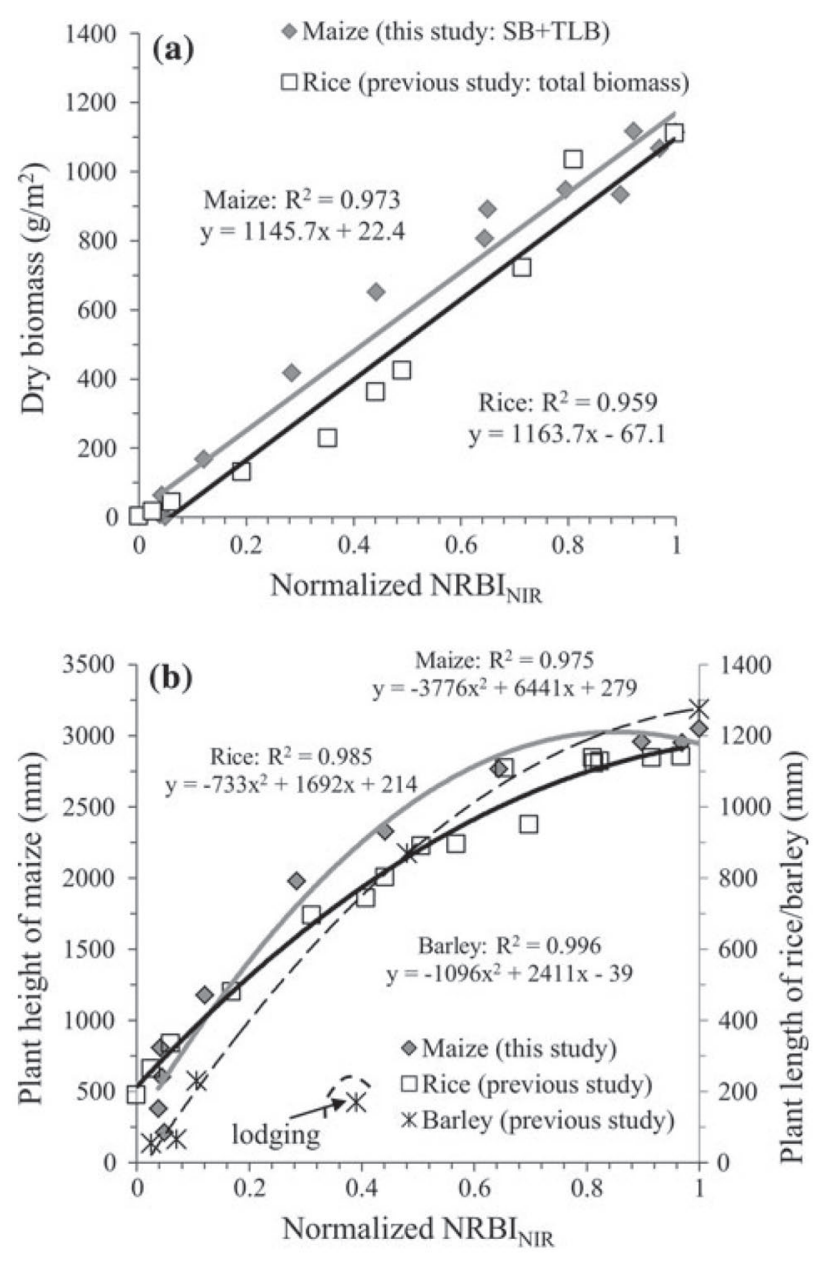

Figure 8. Comparison of normalized $\mathrm{NRBI}_{\mathrm{NIR}}$ with (a) the above-ground dry biomass, and (b) the plant height/length.

mental conditions and with different camera models. Then it is also necessary to investigate the additional possibility of the camera-based observation system with a different calibration approach based on previously-acquired calibration data for another use such as field mapping. Although there are still many technical challenges to make the CPRS practical for actual farm operations, the experimental results found that the green LAI and the total LAI could be separately evaluated by the different camera-based vegetation indices (VARI and 2g-r-b). In addition, the results clearly suggested that the unique fixed-point observation taking night-time NIR images with flash light enabled assessment of another type of bio-physical parameter of maize (TLB + SB) with which both VARI and 2g-r-b had lower correlations.

\section{Conclusion}

This study explored the potential of a camera-based observation system using three camera-derived vegetation indices (VARI, $2 \mathrm{~g}-\mathrm{r}-\mathrm{b}$, and $\mathrm{NRBI}_{\mathrm{NIR}}$ ) for quanti- 
tative monitoring of seasonal changes in several biophysical parameters of maize such as green and total LAI, green and total leaf biomass, and dry stalks and leaf biomass. It was found that each vegetation index was best in evaluating a different biophysical parameter of maize. The VARI was more accurate in estimating green LAI and green leaf biomass, while the $2 \mathrm{~g}-\mathrm{r}-\mathrm{b}$ was more accurate in assessing the total LAI and total leaf biomass. The $\mathrm{NRBI}_{\mathrm{NIR}}$ derived from the night-time NIR images was closely related with the above-ground dry biomass (stalks + leaves) excluding the reproductive organs. It was also confirmed that the $\mathrm{NRBI}_{\mathrm{NIR}^{\prime}}$ which introduces the new concept of night-time flash images using the camera's ISO sensitivity, has a unique sensitivity to the three-dimensional geometry of maize canopy structure unlike traditional VIs calculated from day-time observations. However, as far as the result using the specific camera model is concerned, this study found that the weakness of $\mathrm{NRBI}_{\mathrm{NIR}}$ was that it could not track the increase in the vegetation fraction during the early vegetative stage (i.e., until DOY 160). This was because of the low sensitivity caused by insufficient illumination intensity of the built-in camera flash. There is still an unavoidable problem with using a digital camera for crop growth monitoring: specific calibration has first to be undertaken for each experimental condition and camera model. However, the results suggest that the fixedcamera observations using the modified and non-modified commercially-available cameras have great potential for monitoring and recording the seasonal changes in maize growth at low cost. The use of the three camera-based VIs, VARI, $2 \mathrm{~g}-\mathrm{r}-\mathrm{b}$ and $\mathrm{NRBI}_{\mathrm{NIR}}$, makes it possible to quantitatively evaluate the seasonal changes in the essential biophysical parameters of maize including the green LAI, total LAI, green biomass and the above-ground dry biomass.

Acknowledgments - We gratefully acknowledge the use of facilities and equipment provided by the National Drought Mitigation Center (NDMC), University of Nebraska-Lincoln (UNL). We are grateful to Dr. Don Wilhite, Dr. Mike Hayes, Mr. Todd Schimelfenig and Ms. Deborah Wood of SNR for their valuable comments and research support. We offer special thanks to Mr. Tom Lowman, Lab Manager at Agricultural Meteorology Lab at Mead, for his technical support on the field investigation and the observation equipment, and to Mr. Dave Scoby for his technical support of the plant measurements of maize. We would like to thank Kazuhiro Morita in the Toyama Prefectural Agricultural Forestry and Fisheries Research Center, Wataru Takahashi in the Toyama Prefectural Office, Agriculture, Forestry and Fisheries Department, Dr. Eiji Takada, Mr. Akihiro Inoue in the Toyama National College of Technology, Shigenori Miura in National Agricultural Research Center and Mr. Akihiko Kimura in Kimura Ouyo-Kougei, Ltd for their supports of field measurement and providing agronomic-survey data of rice and barley. This work was supported by the Japanese Society for the Promotion of Science; JSPS Postdoctoral Fellowships for Research Abroad.

\section{References}

Ciganda, V., Gitelson, A., \& Schepers, J. (2008). Vertical profile and temporal variation of chlorophyll in maize canopy: Quantitative "Crop Vigor" indicator by means of reflectance-based techniques. Agronomy Journal, 100(5), 1409-1417.

Cowling, S. A., \& Field, C. B. (2003). Environmental control of leaf area production: Implications for vegetation and land-surface modeling. Global Biogeochemical Cycles, 17(1), 1-14. doi: 10.1029/2002GB001915. 
Gitelson, A. A., Kaufman, Y. J., Stark, R., \& Rundquist, D. (2002). Novel algorithms for remote estimation of vegetation fraction. Remote Sensing of Environment, 80(1), 76-87.

Law, B. E., Arkebauer, T., Campbell, J. L., Chen, J., Sun, O., Schwartz, M., van Ingen, C., \& Verma, S. (2008). Terrestrial carbon observations: Protocols for vegetation sampling and data submission. Report 55, Global Terrestrial Observing System. Rome: FAO.

Matsuda, M., Ozawa, S., Hosaka, Y., Kaneda, K., \& Yamashita, H. (2003). Estimation of plant growth in paddy field based on proximal remote sensing-Measurement of leaf nitrogen contents by using digital camera. Journal of the Remote Sensing Society of Japan, 23(5), 506-515 (in Japanese with English abstract).

Meyer, G. E., Hindman, T. W., \& Laksmi, K. (1999). Machine vision detection parameters for plant species identification (G. E. Meyer, \& J. A. DeShazer, eds.) (pp. 327-335). Boston, MA, USA: SPIE.

Meyer, G. E., \& Neto, J. C. (2008). Verification of color vegetation indices for automated crop imaging applications. Computers and Electronics in Agriculture, 63(2), 282-293.

Perez, A. J., Lopez, F., Benlloch, J. V., \& Christensen, S. (2000). Colour and shape analysis techniques for weed detection in cereal fields. Computers and Electronics in Agriculture, 25(3), 197-212.

Richardson, A. D., Jenkins, J. P., Braswell, B. H., Hollinger, D. Y., Ollinger, S. V., \& Smith, M. L. (2007). Use of digital webcam images to track spring green-up in a deciduous broadleaf forest. Oecologia, 152(2), 323-334.

Ritchie, S. W., Hanway, J. J., Benson, G., \& Herman, J. (2005). How a corn plant develops. Ames, IA, USA: Iowa State University of Science and Technology Cooperative Extension Service.

Sakamoto, T., Shibayama, M., Takada, E., Inoue, A., Morita, K., Takahashi, W., et al. (2010). Detecting seasonal changes in crop community structure using day and night digital images. Photogrammetric Engineering and Remote Sensing, 76(6), 713-726.

Sakamoto, T., Shibayama, M., Kimura, A., \& Takada, E. (in press). Assessment of digital camera-derived vegetation indices in quantitative monitoring of seasonal rice growth. ISPRS Journal of Photogrammetry and Remote Sensing.

Tucker, C. J. (1979). Red and photographic infrared linear combinations for monitoring vegetation. Remote Sensing of Environment, 8(2), 127-150.

Woebbecke, D. M., Meyer, G. E., Vonbargen, K., \& Mortensen, D. A. (1995). Color indices for weed identification under various soil, residue, and lighting conditions. Transactions of the ASAE, 38(1), 259-269. 